\title{
Assessing Community Health Governance for Evidence-informed Decision- making: A Cross-sectional Study Across Nine Districts of India
}

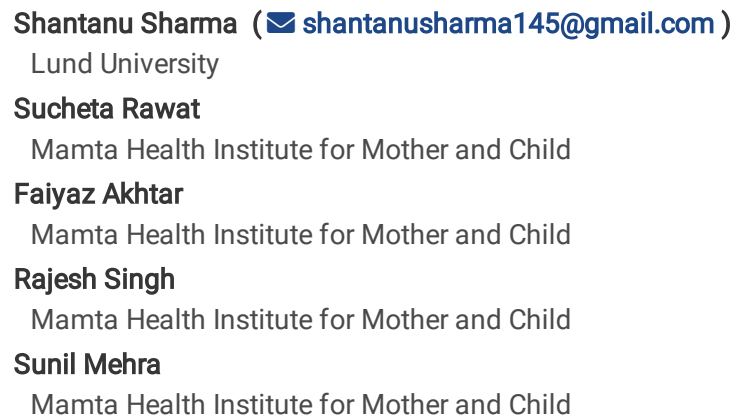

\section{Research Article}

Keywords: Community Health Planning, Community Participation, Community Health Workers, Health Services

Posted Date: February 1st, 2021

DOI: https://doi.org/10.21203/rs.3.rs-144133/v1

License: (c) (1) This work is licensed under a Creative Commons Attribution 4.0 International License. Read Full License

Version of Record: A version of this preprint was published at International Journal of Health Governance on December 24th, 2021. See the published version at https://doi.org/10.1108/IJHG-05-2021-0051. 


\section{Abstract}

\section{Background}

Village Health Sanitation and Nutrition Committee (VHSNC) is a key mechanism to effectuate community health governance in India. VHSNCs enable community members to participate in 'decentralized health planning' and take actions collectively to achieve improved health outcomes in the villages. However, limited studies have evaluated the functioning of VHSNCs comprehensively. We intend to assess the VHSNCs on six parameters, including their formation, composition, meeting frequencies, activities, supervisory mechanisms, and funds receipt and expenditures across nine districts of the three states of India.

\section{Methods}

The cross-sectional study, conducted in the states of Uttar Pradesh ( 5 districts), Odisha (2 districts), and Rajasthan ( 2 districts), used a quantitative research design. The community health workers of 140 VHSNCs, who are also the members of VHSNCs, were interviewed using a semi-structured questionnaire. The details about the funds' receipt and expenditures were verified from the VHSNC records (cashbook). Additionally, we asked about the role of health workers in the VHSNC meetings and the issues and challenges faced.

\section{Results}

The average number of members in VHSNCs varied from 10 in Odisha to 15 in Rajasthan. Activities were regularly organized in Rajasthan and Odisha (one per month) compared to Uttar Pradesh (one every alternate month). Most commonly, health promotion activities, cleanliness drives, community monitoring, and facilitation of service providers were done by VHSNCs. Funds were received regularly in Odisha compared to Rajasthan and Uttar Pradesh. Funds were received late and less compared to the demands or needs by VHSNCs. Supervisory visits to VHSNCs were made most commonly by the medical officer in charge of the primary health centers and chief medical officers at the district.

\section{Conclusion}

This comprehensive analysis of VHSNCs' functioning in the selected study areas sheds light on the gaps in many components, including the untimely and inadequate receipt of funds, poor documentation of expenditures and involvement of VHSNC heads, and inadequate supportive supervision and monitoring. These gap areas need to be addressed immediately for ensuring effective health planning and quality delivery of services in villages.

\section{Background}

In the move to support democratic decentralization in the health services, community health governance provides the community a platform for greater participation and to get involved in the development programs shaping health systems and policies [1, 2]. Community health governance is an approach towards building social accountability, thereby engaging citizens in the governance of public health services and holding government and health service providers accountable. This will strengthen the quality and equity of public health services [3]. There is emerging evidence of people's participation in health governance globally, especially in low- and middle-income countries like India, Cuba, Tanzania, Zambia, and the Philippines [2, 4]. These countries created health committees at the village level to ensure community participation in health planning and development of their areas [4].

In 2005 under the flagship program of the National Health Mission, Village Health Sanitation and Nutrition Committees (VHSNCs) were constituted as a key mechanism to effectuate community health governance in India [2]. The committee was formed to initiate dialogue and decision-making among people for health and its social determinants in the villages [5]. It is visualized that VHSNCs will enable community members to take part in 'decentralized health planning' and take actions collectively to achieve improved health outcomes in the villages. VHSNC serves as a part of gram panchayat (Village Council) and is constituted by community health workers (Accredited Social Health Activists, ASHA, and Anganwadi Workers, AWW), frontline health providers (Auxiliary Nurse Midwife), locally elected representatives, and members from the community $[2,6]$.

VHSNCs are envisaged to conduct monthly meetings, health planning at the local level, and monitor health, sanitation, nutrition, and hygiene services. VHSNCs receive an annual untied fund of INR 10000 (USD 150) from fulfilling the health needs of the people [2, 6]. Furthermore, VHSNC facilitates the organization of Village Health Sanitation and Nutrition Day (VHSND), supports ANM, AWW, and ASHA in conducting VHSND, and ensures the availability of amenities at the VHSND site. VHSND should be observed every month in a village. VHSND is conceptualized as a community-level strategy for convergent actions on health, nutrition, and hygiene. It is a platform of awareness generation and counselling for behavior change besides providing primary health care, including immunization, antenatal care, nutrition, growth monitoring, and early childhood development [7]. VHSNC supports the development of a village health plan to reflect the requirement of resources, infrastructures, and provisions and presents the plan to the local administration [6].

However, there are wide variations in the performance of VHSNC across the country. The twelfth common review mission, conducted by the government of India, revealed that only fewer VHSNCs are functional, and there is a lack of clarity in the roles among VHSNC members. Furthermore, the meetings are organized infrequently, and untied funds are poorly utilized [8]. Barring the government-sponsored monitoring of the VHSNCs (review mission), there are fewer studies that have studied the VHSNCs' functioning $[2,4,9,10]$. Furthermore, the assessments in the previous studies are limited to certain parameters of VHSNC and not entailing a wide range of parameters, including its formation, activities, and monitoring.

Considering the limited evidence and the need to study VHSNC comprehensively for improving its implementation, our paper intends to fill in the research gap. In the present study, we intend to assess the VHSNCs on six parameters, including their formation, composition, meeting frequency, activities, supervisory mechanisms, and funds' receipt and expenditures across selected districts of the three states of India. 


\section{Methods}

The study was nested within a community-based intervention focused on improving the health, nutrition, and hygiene conditions of pregnant and lactating women, adolescents, and young women across three states in India. The details of the intervention are published elsewhere [11]. Strengthening VHSNC functioning through regular meetings with its members was one of the objectives of the intervention. The data presented in the paper were collected as a part of the baseline study of the three-year intervention conducted between 2019 and 2021.

\section{Study population and sampling}

The study was conducted in three states situated in the three zones of India, namely East (Odisha), Centre (Uttar Pradesh), and North (Rajasthan). As per the need for the intervention, we opted for five districts from Uttar Pradesh (Banda, Kaushambi, Lucknow, Prayagraj, and Varanasi), two from Rajasthan (Churu and SriGanaganagar), and two from Odisha (Balangir and Nuapada). The maternal and child health indicators of the three states are shown in Table 1. The study areas include one block from each district. However, in Odisha, two blocks per district were selected (Figure 1). We randomly selected 12-15 VHSNC per block using a random number table. The health and nutrition services to pregnant and lactating women and adolescents in the villages are provided by community health workers, primarily, Anganwadi workers (AWW), Accredited Social Health Activists (ASHA), and Auxiliary Nurse Midwives (ANM). The village head, also known as Sarpanch, is the head of the VHSNC. Anganwadi centers are mother and child care centers at the village level to provide supplementary food, health education, and early childhood care and development [12].

Table 1

Distribution of demographics and maternal and child health indicators across three states of India

\begin{tabular}{|c|c|c|c|c|}
\hline Variables & Uttar Pradesh & Rajasthan & Odisha & India \\
\hline Percentage of rural population ${ }^{1}$ & 77.7 & 75.1 & 83.3 & 68.8 \\
\hline Percentage of marginalized population (SC/ST) ${ }^{1}$ & 21.3 & 31.3 & 39.9 & 25.3 \\
\hline Female literacy rate ${ }^{1}$ & 59.3 & 52.6 & 64.3 & 65.4 \\
\hline Infant mortality rate ${ }^{1}$ & 43.0 & 37.0 & 40.0 & 32.0 \\
\hline Maternal mortality ratio ${ }^{1}$ per 100000 live births & 197 & 164 & 150 & 113 \\
\hline Institutional delivery rate ${ }^{2}$ & 67.8 & 84.0 & 85.0 & 78.9 \\
\hline Percentage of children aged $12-23$ months fully immunized ${ }^{2}$ & 51.1 & 54.8 & 78.6 & 62.0 \\
\hline Percentage of children under 5 who are underweight ${ }^{2}$ & 39.5 & 36.7 & 34.4 & 35.8 \\
\hline Percentage of households covered by improved sanitary facilities ${ }^{2}$ & 35.0 & 45.0 & 29.4 & 48.4 \\
\hline \multicolumn{5}{|l|}{ Source: ${ }^{1}$ Census $2011 ;{ }^{2}$ National Family Health Survey $2014-15$} \\
\hline All figures are in percentage except Maternal Mortality Ratio & & & & \\
\hline
\end{tabular}

\section{Study design and questionnaire}

The study had a quantitative research design. We conducted a cross-sectional quantitative survey of 140 VHSNCs across nine districts. The survey was designed to assess six parameters of VHSNCs, including their formation, composition, meeting frequency, activities, supervisory mechanisms, and funds' receipt and expenditures. The survey was conducted by ten trained research assistants over four months who were given a two-day training on a pre-tested questionnaire. The respondents included AWW, ASHA, or ANM members of the committees. The assistants were introduced to the community health workers by the project staff initially, and prior appointment for the survey was sought.

We developed a semi-structured questionnaire consisting of the following questions related to each of the six parameters: formation (year of formation of VHSNCs and distance from the parent health facility), composition (number of members), fixed date of meetings (yes/no), frequency of the meetings (monthly, bimonthly, quarterly, half-yearly), number of the meetings held since formation and in the last six months, and activities (number of major activities in the last 12 months, including for health promotion, facilitation of service delivery, community monitoring, village health preparation, community audits, and cleaning events, and services monitored by VHSNC members). Furthermore, the questionnaire consisted of the following questions: supervisory mechanisms (visits by officials, such as medical officers and program managers to VHSNCs, and frequency of such visits), funds' receipt and expenditures (funds received in the last three years, funds spent, and funds generated). Additionally, we asked about the role of ASHA in the VHSNC meetings, and the issues and challenges faced. The interviews were conducted in a paper-based format in the local language (Hindi or Odiya). The details about the funds' receipt and expenditures were verified from the VHSNC records (cashbook).

\section{Ethical approval}


The study was granted ethical approval by MAMTA Institutional Review Board (MERB/Sep-2019/002). Written informed consent was obtained from the respondents. Confidentiality of all the respondents and their information was ensured.

\section{Statistical analysis}

We represented continuous variables as mean (standard deviation, SD) for normally distributed data or median (interquartile range, IQR) for skewed data. The categorical variables were presented as frequency (percentages). The data were entered and analyzed using SPSS version 25.0 (IBM Corp., 145 Armonk, N.Y., USA).

\section{Results}

As shown in Table 2, more than three-fourths of the VHSNCs started more than six years ago compared to the VHSNCs in Uttar Pradesh, where around 90\% aged less than six years. The average number of members in VHSNCs varied from 10 in Odisha to 15 in Rajasthan. Most of the VHSNCs in Odisha received funding in 2017-18 as well as 2018-19 compared to less than two-thirds in Rajasthan and Uttar Pradesh in 2018-19.

Table 2

VHSNC formation, composition, meeting frequency, and funds receipt across three states

\begin{tabular}{|c|c|c|c|}
\hline Variables & Uttar Pradesh $(n=62)$ & Rajasthan $(n=30)$ & Odisha $(n=48)$ \\
\hline Number of years since formation & $27(43.5)$ & $1(3.3)$ & $1(2.1)$ \\
\hline$\leq 2.5$ & $28(45.2)$ & $5(16.7)$ & $1(2.1)$ \\
\hline $2.51-6.0$ & $7(11.3)$ & $24(80.0)$ & $46(95.8)$ \\
\hline \multicolumn{4}{|l|}{$>6.0$} \\
\hline Distance from the parent facility in km; median (IQR) & $7(4-12)$ & $6(2.7-10.2)$ & $11(5-20)$ \\
\hline Number of members in VHSNC & $12(10-15)$ & $15(15-15)$ & $10(7-12)$ \\
\hline Fixed date of holding meetings & $52(84.0)$ & $30(100)$ & $36(75.0)$ \\
\hline Yes & $10(16.0)$ & - & $12(25.0)$ \\
\hline \multicolumn{4}{|l|}{ No/Don't know } \\
\hline Frequency of meetings & $\mathrm{n}=52$ & $\mathrm{n}=30$ & $n=36$ \\
\hline Monthly & $48(92.3)$ & $30(100)$ & $32(88.8)$ \\
\hline Bi-monthly/Half-yearly & $4(7.7)$ & - & $4(11.2)$ \\
\hline Number of meetings in the last 6 months* & 6 & 6 & $3(2-6)$ \\
\hline Funds received in 2017-2018 & $37(59.7)$ & $30(100)$ & $46(95.8)$ \\
\hline Yes & $25(40.3)$ & - & $2(4.2)$ \\
\hline \multicolumn{4}{|l|}{ No } \\
\hline Funds received in 2018-2019 & $33(53.2)$ & $18(60.0)$ & $46(95.8)$ \\
\hline Yes & $29(46.8)$ & $12(40.0)$ & $2(4.2)$ \\
\hline \multicolumn{4}{|l|}{ No } \\
\hline Funds received in 2019-2020 & $49(79.0)$ & $9(30.0)$ & $48(100)$ \\
\hline Yes & $13(21.0)$ & $21(70.0)$ & - \\
\hline \multicolumn{4}{|l|}{ No } \\
\hline Bank balance status at the time of the interview (INR) & $150(0-3145)$ & $952(495-1939)$ & $1750(0-7250)$ \\
\hline \multicolumn{4}{|c|}{ Abbreviations: INR: Indian Rupees, VHSNC: Village Health Sanitation and Nutrition Committee, } \\
\hline \multicolumn{4}{|l|}{${ }^{*} \mathrm{QQR}$ was $6-6$ for all the states } \\
\hline The data are expressed in median (Interquartile Rang & frequency (Percent & & \\
\hline
\end{tabular}

Activities were regularly organized in Rajasthan and Odisha (one per month) compared to Uttar Pradesh (one every alternate month) (Table 3). Most commonly, health promotion activities, cleanliness drives, community monitoring, and facilitation of service providers were done by VHSNCs. However, VHSNDs were not held regularly in Odisha and Uttar Pradesh. ASHA and AWW were present in every VHSNC meeting across all the states (Table 4). On the contrary, Sarpanchs had never been present in $60 \%$ of the VHSNC meetings in Odisha. Village health plans were made by most of the VHSNCs in Uttar Pradesh and Rajasthan compared to $58 \%$ in Odisha. 
Table 3

Distribution of activities conducted by VHSNCs across three states

\begin{tabular}{|c|c|c|c|}
\hline Variables & Uttar Pradesh $(n=62)$ & Rajasthan $(n=30)$ & Odisha $(n=48)$ \\
\hline Number of major activities in the last 12-months & $6(1-12)$ & $12(8-12)$ & $12(4-20)$ \\
\hline Local collective action for health promotion activity & $47(75.8)$ & $30(100)$ & $39(81.2)$ \\
\hline Yes & $15(24.2)$ & - & $9(18.8)$ \\
\hline \multicolumn{4}{|l|}{ No } \\
\hline Facilitation of service delivery and service provider & $50(80.6)$ & $30(100)$ & $45(93.7)$ \\
\hline Yes & $12(19.4)$ & - & $3(5.3)$ \\
\hline \multicolumn{4}{|l|}{ No } \\
\hline Community monitoring of health facilities & $47(75.8)$ & $29(96.6)$ & $33(68.7)$ \\
\hline Yes & $15(24.2)$ & $1(3.4)$ & $15(31.3)$ \\
\hline \multicolumn{4}{|l|}{ No } \\
\hline Meeting for preparation of village health plan & $49(79.0)$ & $30(100)$ & $28(58.3)$ \\
\hline Yes & $13(21.0)$ & - & $14(41.7)$ \\
\hline \multicolumn{4}{|l|}{ No } \\
\hline Organizing community dialogue (Jan Samwad) & $38(61.3)$ & $29(96.6)$ & $18(37.5)$ \\
\hline Yes & $24(38.7)$ & $1(3.4)$ & $30(62.5)$ \\
\hline \multicolumn{4}{|l|}{ No } \\
\hline Organizing events like cleaning drive and vector control & $56(90.3)$ & $30(100)$ & $39(81.2)$ \\
\hline Yes & $6(9.7)$ & - & $9(18.8)$ \\
\hline \multicolumn{4}{|l|}{ No } \\
\hline Regular VHSND held in the last 6 months & $38(61.3)$ & $26(86.7)$ & $31(64.6)$ \\
\hline Yes & $24(38.7)$ & $4(13.3)$ & $17(35.4)$ \\
\hline \multicolumn{4}{|l|}{ No } \\
\hline Do you spend money out of VHSNC fund to organize VHSND? & $35(56.5)$ & $29(96.6)$ & $35(73.0)$ \\
\hline Yes & $27(43.5)$ & $1(3.4)$ & $13(27.0)$ \\
\hline \multicolumn{4}{|l|}{ No } \\
\hline Abbreviations: VHSNC: Village Health Sanitation and Nutrition & ommittee, VHSND: Vills & Health Sanitation & d Nutrition Day \\
\hline
\end{tabular}


Table 4

Distribution of supervisory visits to VHSNC and monitoring activities by VHSNCs across three states

\begin{tabular}{|c|c|c|c|}
\hline Variables & Uttar Pradesh (n= 62) N(\%) & Rajasthan $(n=30) N(\%)$ & Odisha $(n=48) N(\%)$ \\
\hline Visit by Sarpanch & $36(58.0)$ & $30(100)$ & $4(8.3)$ \\
\hline Every time & $23(37.0)$ & - & $15(31.2)$ \\
\hline Sometime & $3(5.0)$ & - & $29(60.5)$ \\
\hline \multicolumn{4}{|l|}{ Never } \\
\hline ASHA & $62(100)$ & $30(100)$ & $48(100)$ \\
\hline \multicolumn{4}{|l|}{ Every time } \\
\hline AWW & $62(100)$ & $30(100)$ & $48(100)$ \\
\hline \multicolumn{4}{|l|}{ Every time } \\
\hline AWW helper & $58(93.6)$ & $28(93.4)$ & $38(79.2)$ \\
\hline Every time & $2(3.2)$ & $2(6.6)$ & $7(14.6)$ \\
\hline Sometimes & $2(3.2)$ & - & $2(4.2)$ \\
\hline \multicolumn{4}{|l|}{ Never } \\
\hline ANM & $55(88.8)$ & $28(93.4)$ & $35(73.0)$ \\
\hline Every time & $6(9.6)$ & $1(3.3)$ & $12(25.0)$ \\
\hline Sometimes & $1(1.6)$ & $1(3.3)$ & $1(2.0)$ \\
\hline \multicolumn{4}{|l|}{ Never } \\
\hline Supervisory visit in the last year & $56(90.3)$ & $25(83.3)$ & $32(66.7)$ \\
\hline Yes & $6(9.7)$ & $5(16.7)$ & $16(33.3)$ \\
\hline \multicolumn{4}{|l|}{ No } \\
\hline Frequency of supervisory visits & $\mathrm{n}=56$ & $\mathrm{n}=25$ & $\mathrm{n}=32$ \\
\hline Monthly/ Bimonthly & $14(25.0)$ & $25(100)$ & $19(60.0)$ \\
\hline Quarterly/ Half-yearly & $42(75.0)$ & - & $13(40.0)$ \\
\hline Supervisors during the visit verified accounts of VHSNC & $n=56$ & $\mathrm{n}=25$ & $n=32$ \\
\hline Yes & $20(35.7)$ & $17(68.0)$ & $20(62.5)$ \\
\hline No & $36(64.3)$ & $8(32.0)$ & $12(37.5)$ \\
\hline Made a village health plan & $52(83.9)$ & $29(96.7)$ & $28(58.4)$ \\
\hline Yes & $10(16.1)$ & $1(3.3)$ & $20(41.6)$ \\
\hline \multicolumn{4}{|l|}{ No } \\
\hline Made a list of vulnerable populations & $36(58.0)$ & $15(50.0)$ & $24(50.0)$ \\
\hline Yes & $26(42.0)$ & $15(50.0)$ & $24(50.0)$ \\
\hline No & & & \\
\hline
\end{tabular}




\begin{tabular}{|c|c|c|c|}
\hline Variables & Uttar Pradesh $(n=62) N(\%)$ & Rajasthan $(n=30) N(\%)$ & Odisha $(n=48) N(\%)$ \\
\hline Services monitored in the last 6 months & $53(85.4)$ & $28(93.4)$ & 39 (81.2) \\
\hline Anganwadi center, Yes (\%) & $41(66.1)$ & $9(30.0)$ & 15 (31.2) \\
\hline Sub-center, Yes (\%) & $51(82.2)$ & $26(86.7)$ & $28(58.4)$ \\
\hline Village Health and Nutrition Day, Yes (\%) & $51(82.2)$ & $13(43.4)$ & $31(64.5)$ \\
\hline ASHA for institutional delivery, Yes (\%) & $29(46.8)$ & $29(96.7)$ & 0 \\
\hline Mid-day Meal, Yes (\%) & & & \\
\hline
\end{tabular}

Supervisory visits to VHSNCs were made most commonly by the medical officer in charge of the primary health centers, chief medical officer at the district, and child development project officer of Anganwadi centres. Other stakeholders, such as district program managers and health education officers, did visit VHSNCs occasionally.

During the interview, it was revealed that money received by VHSNCs was less compared to the demands or needs, and whatever received was spent mostly. The respondents informed that the funds were received in the second half of the year (a delayed receipt of money). Furthermore, there were improper entries of the expenditures made by the VHSNC members, and there had been issues of withdrawing money out from the bank. In the interviews, respondents acknowledged that some issues persisted in villages like improper hygiene or sanitation despite being raised in the meetings. In addition, respondents perceived that members of VHSNCs did not have adequate knowledge and were not aware of their roles and responsibilities. There was a lack of cooperation or support from the community to VHSNCs.

\section{Discussion}

Our study contributed to the little evidence available on the assessment of community health governance in one of the largest democracies of the world, India. In our study, most of the VHSNCs in Rajasthan and Odisha started more than six years ago compared to Uttar Pradesh. This could probably be because VHSNCs were non-active in Uttar Pradesh for many years, or the respondents did not have the previous records [13]. The number of members in VHSNCs in most of the studies, including our study, are in accordance with the guidelines except Odisha [14,15]. On the contrary, some studies reported that the VHSNCs did not have a minimum number of members in the committee [10]. Not just the numbers, the VHSNC guidelines set forth the recommendation to have representatives from the marginalized classes in the committee. However, most studies echoed that marginalized classes are poorly represented or heard or taken seriously even if represented in such committees $[15,16,17]$. This poor representation of the marginalized classes in the meetings connotes the caste and power dynamics in villages.

Unlike most of the studies, we reported that VHSNC meetings occurred regularly [10,14-18]. However, similar to ours, another study from Maharashtra reported regular VHSNC meetings [19]. Studies acknowledged reasons such as bad weather conditions or the busy schedule of VHSNC members for irregular meetings [10]. In our study, most of the VHSNCs had a fixed date for holding the meetings. We argue that a fixed date of meeting every month may prompt the members to attend it regularly. Furthermore, proper records of all the meetings should be entered in the registers with key discussion points, actions to be taken, and members present in the meeting.

In other studies, most of the VHSNCs received funds but more than $50 \%$ did not spend half of its amount [16]. A lot of funds had been spent on administrative purposes and not on the activities. In fact, some studies highlighted that the frontline workers were pressured to spend funds on personal use of Sarpanchs $[10,17]$. Furthermore, records and registers were not updated as per the norms of all the meetings $[9,14,15]$. Our study echoed the previous findings that funds were limited, and there was a delay in payments to VSHNCs [17]. Despite the delay in receiving the funds, most of the VHSNCs utilized them well [9,14,15]. We found that limited balance was left in the accounts of the VHSNCs as most of it had been spent on the activities. However, the documentation of untied funds in the registers was poor. Most of the studies highlighted that the registers were not updated $[9,20]$. The accountability and transparency of the expenditures are crucial pillars of good governance and means to bring reforms in public health. Within the ambit of good governance, the limited resources can be used judiciously, and services are provided efficiently and effectively [21]. To encounter delays in the payments or release of funds, the government is planning to start the financial year from $1^{\text {st }}$ January [22].

Like other studies, Sarpanch's involvement in the meetings was poor and not regular in most places $[15,17,18]$. Different reasons identified for the poor engagement of Sarpanchs in the VHSNC meetings include since members did not get any remuneration for organizing the VHSNC meetings, they were not interested in doing it. Secondly, most of the Sarpanchs were not well educated or illiterate, so they could not envisage the benefits of organizing VHSNC meetings for making annual health plans of villages, community events for health promotion, etc. Thirdly, Sarpanchs were more interested in organizing such meetings in closed groups to negotiate with people for votes [17]. On the contrary, the workload and hassle of record-keeping of the meetings discouraged ANM from participating in these meetings regularly [15,17].

Cleanliness drive and awareness generation were the common activities performed by VHSNC [9,15]. The scope of VHSNC work was limited to a few activities and there has been an emerging need to broaden the horizon of its work, especially post COVID-19 [23]. VHSNC members, particularly Sarpanchs, were not aware of their roles and responsibilities; some of them did not even know if they were the members. While members had not been trained on VHSNCs guidelines in many places, the training was inadequate at other places [15,19]. Many were uninformed about how to spend the untied funds [19]. Most of the trainings for VHSNC members work on a cascade model that trains only frontline workers, primarily ASHA, who are supposed to conduct training for other members. Similarly, the guidelines propose repeated trainings at regular intervals, all of which are not implemented effectively at the ground level, resulting in 
most members being unaware of their roles and responsibilities [2,6]. Furthermore, repeated training needs to be emphasized as Sarpanchs are elected representatives that change every $4-5$ years [6].

VHSNCs are involved in organizing VHSND, but they were not organizing it regularly as described in our study. Likewise, it has been reported in other studies that VHSNDs were held inconsistently $[15,17]$. VHSNDs are established by the government as a unique platform to bring a convergence of health, nutrition, and sanitation services at a primary care level on a monthly basis. Furthermore, VHSNDs are proposed to deliver a package of services, including registration of pregnant women, immunization and growth monitoring of under-5, family planning service provision, and health education [24,25]. Irregular and improperly organized VHSND can defy the purpose and may leave many children deprived of basic health and nutrition services.

Village health plans were not routinely made by VHSNC, and some studies highlighted that the involvement of Sarpanchs/PRI members in the development of village health plans was limited $[9,15,17]$. The members were unaware of such plans, and documentation of the plans is weak [9,15,19]. Village health plans are important and need micro-financial planning at the village level. This would ensure that the health and nutrition needs of the communities are raised and adequately addressed in the annual district or state health plans.

We found inadequate supportive supervision and monitoring visits by the government officials, such as medical officers, child development project officer, etc. Supportive supervision is an evidence-based strategy to improve the professional competence of the workers, thereby, the quality of services. This two-way communication process helps health workers identify problems, find appropriate solutions, optimize resource allocation, and promote teamwork [26]. The process of supportive supervision needs inter-sectoral convergence wherein the child development project officer from the department of women and child development would coordinate with the medical officer from the department of health and family welfare to improve the functioning of VHSNC by Sarpanchs (answerable to Ministry of Panchayati Raj).

\section{Limitations:}

Our study's results should be interpreted considering the following limitations. Firstly, VHSNC of the selected geographies were selected as the study was a part of an intervention. This limits the generalizability of the findings to all the VHSNC across the country. Secondly, we lacked data on three crucial parameters, which have been captured in many studies, including representation of members from different social backgrounds in VHSNC, education status and gender of the Sarpanch, and the awareness of the roles and responsibilities among VHSNC members. Lastly, community-perspectives on the functioning of VHSNC were not collected. Though the additional data on these parameters would have given a 360-degrees perspective to the analysis, due to limited resources and time, we could not obtain them in our study. However, we propose to overcome these shortcomings in future research.

\section{Conclusion}

VHSNCs are envisaged to ensure community participation in health planning, but their actions and performance are shaped by the contextual factors, such as availability of funds and motivation and willingness of its members to perform. Our study sheds light on the irregular and delayed receipt of funds, lack of supervisory visits by medical officers or ICDS staff, or their assessments of the accounts, non-performance of the key activities, such as making a village health plan, monitoring services, and organizing VHSND. We argue that the poor performance of VHSNC in some of the areas may be linked to multiple factors, including inadequate training of VHSNC members on their key roles and responsibilities. The issues and challenges faced by VHSNC are important and material to our study context and need to be addressed at the policy-level.

\section{Abbreviations}

ANM: Auxiliary Nurse Midwife

ASHA: Accredited Social Health Activist

AWW: Anganwadi Worker

VHSND: Village Health Sanitation and Nutrition Day

VHSNC: Village Health Sanitation and Nutrition Committee

\section{Declarations}

\section{Ethics approval and consent to participate}

The study protocol was approved by the MAMTA Ethical Review Board (MERB). The MERB looks after the study protocols submitted by MAMTA Health Institute for Mother and Child. Written informed consent was obtained from all participants for the use of their data for research. All methods were carried out in accordance with relevant guidelines and regulations.

\section{Consent for publication}

Not applicable. 


\section{Availability of data and materials}

The datasets used and/or analyzed in the present study are available from the corresponding author on reasonable request.

\section{Competing interests}

The authors declare that they have no competing interests.

\section{Funding}

This project of implementation science was granted funding under the Corporate Social Responsibility from Nestlé India. The funders had no role in the study design, intervention framework, data collection and analysis, decision to publish, or preparation of the manuscript.

\section{Authors' contributions}

SS and SR conceived and designed the study. FA and RKS coordinated with the researchers for data collection and cleaned the data. SS and SR analyzed the data. SS drafted the manuscript. SM, SR, RKS, and FA reviewed/consulted the manuscript; SS contributed to the critical revision of the manuscript. All authors commented on drafts and read and approved the final manuscript.

\section{Acknowledgement}

The authors would like to thank the participants of this study for contributing their time. In addition, the authors are grateful for the assistance of field investigators for their help with data collections.

\section{References}

1. Wasnik J. Local Governance Ethics in India: Issues and Challenges. Governance \& Public Policy. 2020;10(1):2-13.

2. Ved R, Sheikh K, George AS, et al. Village Health Sanitation and Nutrition Committees: reflections on strengthening community health governance at scale in India. BMJ Global Health 2018;3:e000681.

3. Gullo, S., Kuhlmann, A.S., Galavotti, C. et al.Creating spaces for dialogue: a cluster-randomized evaluation of CARE's Community Score Card on health governance outcomes. BMC Health Serv Res. 2018;18:

4. Srivastava A, Gope R, Nair N, Rath S, Rath S, Sinha R, Sahoo P, Biswal PM, Singh V, Nath V, Sachdev HP. Are village health sanitation and nutrition committees fulfilling their roles for decentralised health planning and action? A mixed methods study from rural eastern India. BMC Public Health. 2015;16(1):59.

5. Government of India. Guidelines for Community Processes.New Delhi: Ministry of Health and Family Welfare, Government of India; 2013. Available from: http://nhsrcindia.org/community-processes. [Accessed 5 October 2020]

6. Ministry of Health and Family Welfare, Government of India. Handbook for members of village health sanitation and nutrition committee. National Health Mission: New Delhi, India. Available from: https://nhm.gov.in/images/pdf/communitisation/vhsnc/Resources/Handbook_for_Members_of_VHSNCEnglish.pdf. [Accessed 1 September 2020].

7. Ministry of Health and Family Welfare and Ministry of Women and Child Development, Government of India. National guidelines for village, health, sanitation, and nutrition day. National Health Mission: New Delhi, India. Available from:

https://nhm.gov.in/New_Updates_2018/NHM_Components/RMNCHA/CH/Guidelines/National_Guidelines_on_VHSND_English_High_Res_Print_ready.pdf. [Accessed 05 October 2020].

8. Ministry of health and family welfare. $12^{\text {th }}$ Common review mission. Government of India, Delhi, India. Available from: https://nhm.gov.in/New_Updates_2018/Monitoring/CRM/12th/12th-CRM_Report.pdf. [Accessed 15 July 2020].

9. Dhiman A, Khanna P, Singh T. Evaluation of village health sanitation and nutrition committee in Himachal Pradesh, India. J Family Med Prim Care. 2020;9(9):4712-16.

10. Passi R, Goel S, Ajay S. Assessment of village health sanitation and nutrition committees of Chandigarh, India. Indian J Public Health. 2017;61:290-6.

11. Sharma S, Akhtar F, Singh RK, Mehra S. Validation of Health Education Material for Youth: A Step to Ensure Implementation Fidelity in Community-Based Interventions. InHealthcare 2020;8(1):8

12. Saxena NC, Srivastava N. ICDS in India: policy, design and delivery issues. IDS Bulletin. 2009;40(4):45-52.

13. United Nations Development Programme. Impact evaluations of social accountability interventions in Uttar Pradesh.

https://www.worldbank.org/en/programs/sief-trust-fund/brief/impact-of-social-accountability-interventions-on-healthcare-delivery-and-health-outcomesin-uttar-pradesh-india.

14. Das M, Ojah J, Baruah R. The functioning of the Village Health Sanitation and Nutrition Committee. Int J Med Sci Public Health 2016;5:2052-56.

15. Singh R, Purohit B. Limitations in the functioning of Village Health and Sanitation Committees in a North Western State in India. Int J Med Public Health. 2012;2(3):39-46. 
16. Semwal V, Jha SK, Rawat CMS, Kumar S, Kaur A. Assessment of village health sanitation and nutrition committee under NRHM in Nainital district of Uttarakhand. Ind J Comm Health. 2013;25(4):472 - 9.

17. Kumar V, Mishra AJ, Verma S. Health planning through Village Health Sanitation and Nutrition Committees. Int J Health Care Qual Assur. 2016;29(6):70315.

18. Bathula AN, Sripada L, Choudhury LP. Social Accountability and community participation in Village Health Nutrition and Sanitation committees in Uttar Pradesh. Indian J Comm Health. 2020;32(1):108-113.

19. Sah PK, Raut AV, Maliye CH, Gupta SS, Mehendale AM, Garg BS. Performance of village health, nutrition and sanitation committee: A qualitative study from rural Wardha, Maharashtra. The Health Agenda, Online ISSN No: 2320-3749

20. State Health Resource Centre, Government of Chattisgarh. Village Health Sanitation and Nutrition Committees in Chattisgarh: An assessment. 2013. Available from: http://shsrc.org/wp-content/uploads/2020/04/VHSNC_Assessment_Chhattisgarh_2012_Report.pdf. [Accessed 15 November 2020].

21. World Health Organization. Good Governance in the process of public health law reform. Available from: https://www.who.int/healthsystems/topics/health-law/chapter5.pdf [Accessed 14 November 2020].

22. NITI AYOG, Government of India. Need for changing India's financial year: Discussion note. Available from: https://niti.gov.in/writereaddata/files/document_publication/Changing\%20Financial\%20Year.pdf. [Accessed 21 November 2020].

23. Shirin Madon. The potential of India's Village Health Committees in containing the spread of diseases. The London School of Economics and Political Science. https://blogs.Ise.ac.uk/internationaldevelopment/2020/05/15/the-potential-of-indias-village-health-committees-in-containing-the-spread-ofdiseases/.

24. Panigrahi SK, Mohapatra B, Mishra K. Awareness, perception and practice of stakeholders in India regarding Village Health and Nutrition Day. J Family Med Prim Care. 2015;4(2):244-50.

25. Saxena V, Kumar P, Kumari R, Nath B, Pal R. Availability of Village Health and Nutrition Day services in Uttarakhand, India. J Family Med Prim Care. 2015;4(2):251-6.

26. Bhuputra Panda, Sanghamitra Pati, Srinivas Nallala, Abhimanyu S. Chauhan, Anita Anasuya, Meena Som \& Sanjay Zodpey (2015) How supportive supervision influences immunization session site practices: a quasi-experimental study in Odisha, India, Global Health Action, 8:1, 25772.

\section{Figures}

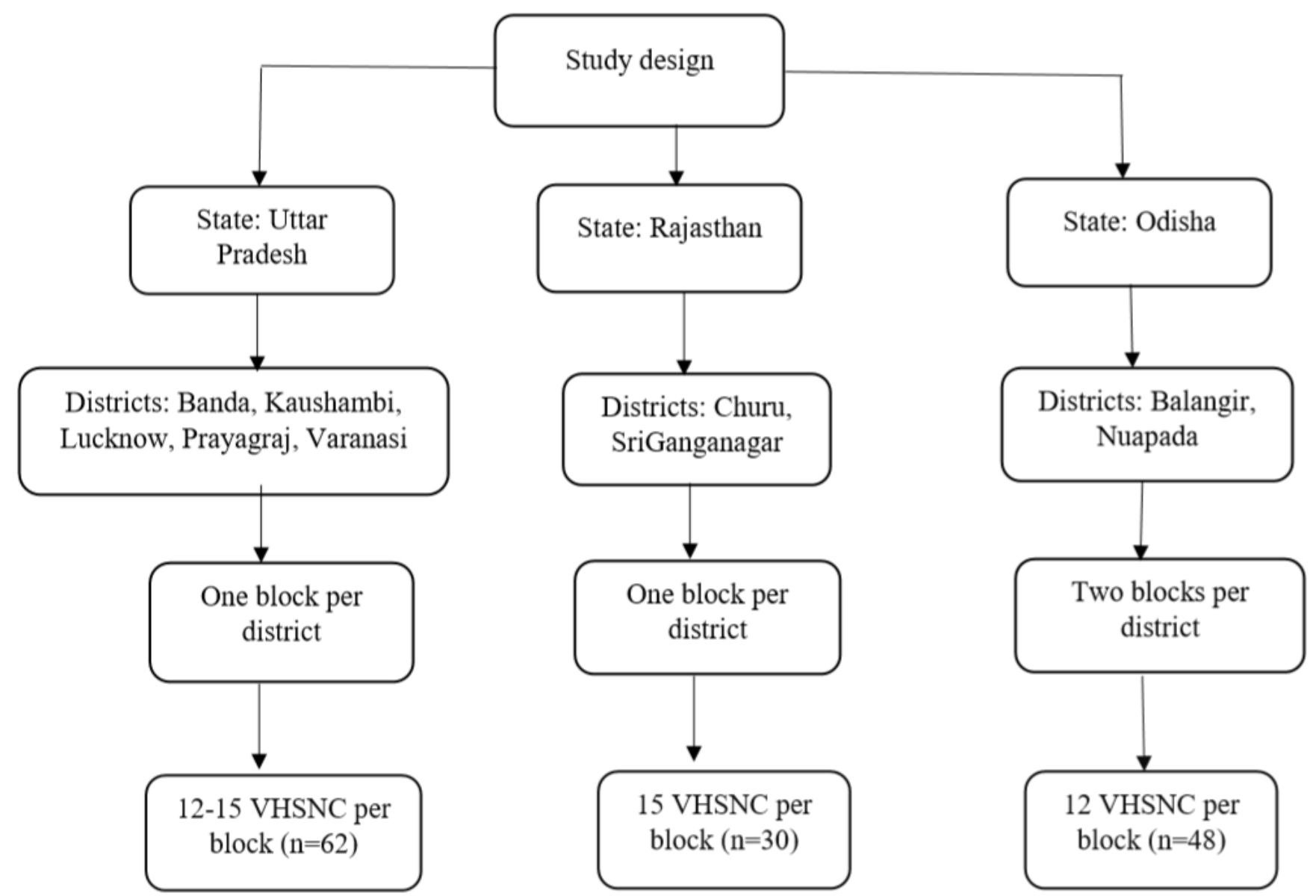

Figure 1 
The figure illustrates the sampling of VHSNCs across three states in India. The sampling includes selecting one block per district and 12-15 VHSNCs per block.

Page 11/11 